\title{
Interleukin-17A Increases Neurite Outgrowth from Adult Postganglionic Sympathetic Neurons
}

\author{
Susan P. Chisholm, ${ }^{1 \star}$ Andrea L. Cervi, ${ }^{1 \star}$ Simrin Nagpal, ${ }^{2}$ and Alan E. Lomax ${ }^{1,3}$ \\ Departments of ${ }^{1}$ Biomedical and Molecular Sciences, ${ }^{2}$ Biomedical Computing, and ${ }^{3}$ Medicine, Gastrointestinal Diseases Research Unit and Centre for \\ Neuroscience Studies, Queen's University, Kingston, Ontario K7L 2V7, Canada
}

Inflammation can profoundly alter the structure and function of the nervous system. Interleukin (IL)-17 has been implicated in the pathogenesis of several inflammatory diseases associated with nervous system plasticity. However, the effects of IL-17 on the nervous system remain unexplored. Cell and explant culture techniques, immunohistochemistry, electrophysiology, and $\mathrm{Ca}^{2+}$ imaging were used to examine the impact of IL-17 on adult mouse sympathetic neurons. Receptors for IL-17 were present on postganglionic neurons from superior mesenteric ganglia (SMG). Supernatant from activated splenic T lymphocytes, which was abundant in IL-17, dramatically enhanced axonal length of SMG neurons. Importantly, IL-17-neutralizing antiserum abrogated the neurotrophic effect of splenocyte supernatant, and incubation of SMG neurons in IL-17 $(1 \mathrm{ng} / \mathrm{ml})$ significantly potentiated neurite outgrowth. The neurotrophic effect of IL-17 was accompanied by inhibition of voltage-dependent $\mathrm{Ca}^{2+}$ influx and was recapitulated by incubation of neurons in a blocker of $\mathrm{N}$-type $\mathrm{Ca}^{2+}$ channels ( $\omega$-conotoxin GVIA; $30 \mathrm{nM}$ ). IL-17-induced neurite outgrowth in vitro appeared to be independent of glia, as treatment with a glial toxin $(\mathrm{AraC} ; 5 \mu \mathrm{M})$ did not affect the outgrowth response to IL-17. Moreover, application of the cytokine to distal axons devoid of glial processes enhanced neurite extension. An inhibitor of the NF- $\kappa$ B pathway (SC-514; $20 \mu \mathrm{M})$ blocked the effects of IL-17. These data represent the first evidence that IL-17 can act on sympathetic somata and distal neurites to enhance neurite outgrowth, and identify a novel potential role for IL-17 in the neuroanatomical plasticity that accompanies inflammation.

\section{Introduction}

The adult sympathetic nervous system (SNS) displays plasticity of form and function in response to many distinct types of inflammation, both acute and chronic. Acute inflammatory states such as myocardial infarction (Hasan et al., 2006), ozone-induced pulmonary inflammation (Graham et al., 2001), interstitial cystitis (Peeker et al., 2000), and intestinal parasitic infection (Kannan et al., 1996) increase sympathetic innervation density in the afflicted tissues. Chronic autoimmune diseases are also associated with remodeling of sympathetic axons; recent studies of inflammatory bowel disease (IBD) patients and animal models of IBD provided anatomical evidence of increased sympathetic innervation of colonic smooth muscle (Lourenssen et al., 2005), mesenteric blood vessels (Birch et al., 2008), and dorsal root ganglia (Xia et al., 2011). Models of chronic

Received Oct. 23, 2011; revised Nov. 14, 2011; accepted Dec. 2, 2011.

Author contributions: S.P.C., A.L.C., S.N., and A.E.L. designed research; S.P.C., A.L.C., and S.N. performed research; S.P.C., A.L.C., S.N., and A.E.L. analyzed data; S.P.C., A.L.C., and A.E.L. wrote the paper.

This work was supported by grants from the Crohn's and Colitis Foundation of Canada, the Canadian Institutes of Health Research, and the Canadian Association of Gastroenterology (to A.E.L.). S.P.C. was the recipient of a graduate scholarship from a CIHR training grant in digestive sciences. A.L.C. was the recipient of a National Science and Engineering Council Scholarship and an Ontario Graduate Scholarship. We are grateful to Dr. Heather Young for her advice on establishing the explant culture assays, Dr. Humberto Gutierrez for sharing his MATLAB Sholl analysis script, and Dr. Cecilia Berin for advice on isolating and stimulating splenocytes. We thank Drs. Lysa Boissé and Heather Young for insightful comments on the manuscript.

*S.P.C. and A.L.C. contributed equally to this work.

Correspondence should be addressed to Alan E. Lomax, GIDRU Wing, Kingston General Hospital, Stuart Street, Kingston, Ontario K7L 2V7, Canada. E-mail: Iomaxa@queensu.ca.

DOI:10.1523/JNEUROSCI.5343-11.2012

Copyright $\odot 2012$ the authors $\quad 0270-6474 / 12 / 321146-10 \$ 15.00 / 0$ arthritis have demonstrated similar effects on the SNS (Lorton et al., 2009; Straub et al., 2011).

Anatomical remodeling of the SNS often leads to important functional alterations in the system involved. In models of myocardial infarction, the sympathetic outflow to the heart is increased as a result of inflammation-induced SNS hyperinnervation, which has been suggested to increase susceptibility to arrhythmia postinfarction (Hasking et al., 1986; Himura et al., 1993; Eisenhofer et al., 1996). Animal models of neuropathic and inflammatory pain implicate sympathetic sprouting in dorsal root ganglia in the onset and maintenance of mechanical and thermal allodynia (Gibbs et al., 2008). Increased sympathetic axonal sprouting has also been linked to aberrant vascular regulation in obese rats (Haddock and Hill, 2011). Finally, recent evidence from studies of vagally mediated neuroimmunomodulation strongly suggest that sympathetic postganglionic neurons comprise the final motor pathway in the autonomic regulation of inflammation severity in inflammatory diseases (The et al., 2007; Ghia et al., 2008; Rosas-Ballina et al., 2008, 2011; Wong et al., 2011). Given the functional consequences of sympathetic neuroanatomical plasticity during inflammation, a better understanding of the molecular mechanisms and candidate mediators of these effects is required.

Mounting evidence suggests a role for the inflammatory cytokine network in promoting sympathetic axonal remodeling during inflammatory disease (Kannan et al., 1996; Rapalino et al., 1998; Xie et al., 2006; Hyatt Sachs et al., 2010). The extent of sympathetic axonal sprouting following myocardial infarction, for example, is positively correlated with the degree of infiltrating immune cells, which synthesize and secrete proinflammatory 
cytokines (Hasan et al., 2006; Wernli et al., 2009). Interleukin17A (IL-17), the principal cytokine secreted from the novel $\mathrm{T}_{\mathrm{H}} 17$ lineage of helper $\mathrm{T}$ lymphocytes, has recently emerged as a key proinflammatory cytokine that orchestrates immune responses during infection, acute inflammation, allergy, and autoimmune disease (Nakae et al., 2003; Bettelli et al., 2007; Korn et al., 2007; Oboki et al., 2008; Littman and Rudensky, 2010). However, little is known about the effect of IL-17 on the nervous system. Given that IL-17 is implicated in the pathogenesis of the types of inflammation that lead to sympathetic neuroanatomical plasticity, we hypothesized that IL-17 contributes to sympathetic remodeling during inflammation. In the current study, we used immunohistochemistry, neurite outgrowth assays, electrophysiology, and $\mathrm{Ca}^{2+}$ imaging to investigate whether IL-17 induces axon outgrowth from adult mouse sympathetic neurons and identify the signaling mechanisms involved.

\section{Materials and Methods}

\section{Animal care}

All animal care protocols were developed in accordance with the Guidelines of the Canadian Council of Animal Care and were approved by the Queen's University Animal Care Committee. Adult male CD1 mice weighing between 25 and $35 \mathrm{~g}$ were purchased from Charles River and maintained on a 12:12 h light:dark cycle, with access to standard lab chow and tap water ad libitum.

\section{Tissue collection}

Following deep anesthesia by an overdose of inhaled isoflurane, mice were killed by cervical dislocation. The superior mesenteric ganglion (SMG) was dissected and cleaned of all visible adipose tissue before transfer to a vial of prewarmed HBSS. Unless stated otherwise, drugs and reagents were obtained from Sigma.

\section{SMG dissociation}

The SMG was dissociated to yield single neurons as previously described (Motagally et al., 2009a). Briefly, the SMG was subjected to enzymatic dissociation in collagenase solution (Type 1A; $1547 \mathrm{U} / \mathrm{ml}$ ) with bovine serum albumin (BSA; $6 \mathrm{mg} / \mathrm{ml}$ ) in HBSS, followed by trypsin solution (type XII-S; $1500 \mathrm{U} / \mathrm{ml}$ ) with BSA at $37^{\circ} \mathrm{C}$. The SMG was then mechanically dissociated into a suspension of single cells. Cell suspensions of $100-200 \mu \mathrm{l}$ were plated onto laminin $(10 \mu \mathrm{g} / \mathrm{ml})$-coated glass coverslips in a 24-well plate and allowed to adhere for $2.5 \mathrm{~h}$, at which time Leibowitz's (L-15) media supplemented with $24 \mathrm{~mm} \mathrm{NaHCO}_{3}, 10 \%$ fetal bovine serum (FBS), $38 \mathrm{~mm}$ D-glucose, $5000 \mathrm{IU}$ penicillin/streptomycin, and 50 $\mathrm{ng} / \mathrm{ml}$ nerve growth factor (NGF; Cedarlane Laboratories) was added. Recombinant mouse interleukin-17 (Peprotech) was reconstituted in PBS. To study neurite extension in a compartmented culture system, SMG neurons were loaded into a 1 CC syringe fitted with a 28 -gauge Teflon needle (World Precision Instruments) and 50-80 $\mu \mathrm{l}$ of cell suspension were injected into the proximal chamber of a compartmented culture dish.

\section{Explant cultures}

Collagen gels were formed using eight parts acidified rat tail collagen (Roche Molecular Biochemical) reconstituted with one part $10 \times$ concentrated DMEM and one part $10 \times$ concentrated HBSS, and diluted to 1 $\mathrm{mg} / \mathrm{ml}$ with DMEM containing 5\% FBS and $50 \mathrm{ng} / \mathrm{ml} \mathrm{NGF}$, as previously described (Barrett et al., 2005). SMG were placed in collagenase solution for $20 \mathrm{~min}$ to enhance the permeability of the ganglion capsule, rinsed, and cut into four pieces under a dissecting microscope, then each piece was embedded into semisolidified collagen gels. For directional neurite extension assays, Cibicron agarose beads were soaked in either IL-17 (100 $\mathrm{ng} / \mathrm{ml}$ ) in HBSS or HBSS alone for $4 \mathrm{~h}$ at $4^{\circ} \mathrm{C}$. A single bead was then placed 800-900 $\mu \mathrm{m}$ from the ganglion explant, and the explants were cultured for $3 \mathrm{~d}$. Bead position was marked by punching a hole in the gel before immunohistochemical processing.
Table 1. Primary antibodies

\begin{tabular}{lllll}
\hline Reactivity & Host & Source & Concentration & Reference \\
\hline$\beta-3$ tubulin & Rabbit & Sigma & $1: 500$ & Leiss et al., 1988 \\
HuD & Mouse & Invitrogen & $1: 500$ & Antunes et al., 2000 \\
IL-17RA & Goat & R \& D Systems & $1: 50$ & Kao et al., 2005 \\
SNAP-25 & Rabbit & Invitrogen & $1: 4000$ & Geddes et al., 1990 \\
SOX-10 & Goat & Santa Cruz Biotechnology & 1:500 & Liu et al., 2002 \\
TH & Rabbit & Millipore & $1: 500$ & Lourenssen et al., 2005 \\
\hline
\end{tabular}

Table 2. Secondary antibodies

\begin{tabular}{llll}
\hline Reactivity & Host & Source & Concentration \\
\hline Mouse (488) & Goat & Invitrogen & $1: 1000$ \\
Rabbit (555) & Goat & Invitrogen & $1: 2000$ \\
Rabbit (549) & Donkey & Jackson ImmunoResearch & $1: 800$ \\
Goat (488) & Donkey & Jackson ImmunoResearch & $1: 800$ \\
\hline
\end{tabular}

\section{Immunohistochemistry}

Tissue cryosections. Dual-label immunohistochemistry was performed on sections of SMG to examine whether cells in the ganglion expressed the IL-17 receptor A (IL-17R) and tyrosine hydroxylase (TH), a marker of sympathetic neurons. Mice were transcardially perfused with $4 \%$ paraformaldehyde (PFA) in $0.1 \mathrm{~m}$ sodium phosphate buffer while under deep anesthesia (ketamine/xylazine at $0.166 \mathrm{mg} / \mathrm{g}$ ). The SMG were removed and fixed overnight in $4 \%$ PFA at $4^{\circ} \mathrm{C}$, then transferred to $30 \%$ sucrose solution for $24 \mathrm{~h}$. SMG were subsequently embedded in freezing media (Shandon Cryomatrix; Fisher Scientific), frozen in chilled 2-methylbutane, and stored at $-80^{\circ} \mathrm{C}$. Sections $(10$ $\mu \mathrm{m}$ ) were cut using a cryostat (Thermo Shandon; Fisher Scientific) and collected on Superfrost Plus microscope slides.

Cryosections were washed in PBS-Tween $(0.1 \%)$ three times before incubation in $10 \%$ normal donkey serum for $1 \mathrm{~h}$ in a humidified chamber (used for all incubations). Slides were washed three times in PBSTween $(0.1 \%)$, and primary antiserum to IL-17R (Table 1 ) was added to slides overnight. Following removal of primary antiserum, slides were washed an additional three times and incubated in secondary antiserum for $2 \mathrm{~h}$. Slides were then washed three times in PBS-Tween $(0.1 \%)$, immunofluorescently labeled with TH using the same protocol described above, then coverslipped with fluorescence mounting media (DAKO).

\section{Isolated cells and explant cultures}

Cells and tissue were fixed using 4\% PFA in 0.1 m sodium phosphate buffer. Dissociated cells were fixed for $10 \mathrm{~min}$ at room temperature; collagen gels containing explants were fixed overnight at $4^{\circ} \mathrm{C}$. Following removal of the fixative and washes in PBS, the tissues were blocked for $1 \mathrm{~h}$ at room temperature in 5\% normal goat, horse, or donkey serum in PBS with $0.1 \%$ Tween, depending on the species in which the secondary antiserum was raised. Primary antisera to SNAP-25, HuD, $\beta-3$ tubulin, or IL-17R were then added overnight at $4^{\circ} \mathrm{C}$ (for dilutions, see Table 1). Primary antiserum was removed, tissues were washed a further three times in PBS, and an appropriate secondary antibody (Table 2) was added for $1 \mathrm{~h}$ at room temperature. Following three washes in PBS, coverslips were mounted with fluorescence mounting medium (DAKO) and visualized using an epifluorescence microscope (Olympus BX51). Photomicrographs were taken using a Coolsnap CCD camera and ImagePro software.

\section{Quantification}

For HuD/SNAP-25-stained coverslips, every third field of view in the horizontal and vertical axes using a $40 \times$ objective lens was analyzed. The number of HuD-positive neurons in the entire field of view and the number of SNAP-25-positive neurites crossing either the vertical or horizontal midline of the field of view were determined. For real time outgrowth assays, the number of neurons, neurites, branch points, and neurons with neurites on half of each coverslip were recorded. A neurite was included for analysis if it was $>1$ cell body in length. 
For $\beta$-3-tubulin-stained explant cultures in collagen gels, regions of interest (ROI) adjacent to each ganglion were identified on thresholded black-and-white images. An experimental ROI $750 \times 750$ pixels in size was selected on the side of the explant facing the bead. Using ImageJ software (rsbweb.nih.gov/ij/), the total immunofluorescence within the experimental ROI was calculated and compared with a control ROI of the same size on the opposite side of the bead.

To analyze effects of IL-17 on neurite branching complexity, the Sholl analysis (Gutierrez and Davies, 2007) was performed on dissociated SMG neurons cultured for $5 \mathrm{~d}$ in the presence or absence of IL-17. Isolated SMG neurons and neurites were fluorescently labeled by incubation in calcein-AM ( $1 \mu \mathrm{M}$; Invitrogen) for $15 \mathrm{~min}$ at $37^{\circ} \mathrm{C}$ and visualized using a Zeiss axiovert inverted fluorescence microscope. Only neurons with clearly distinguishable processes that were separated from nearby cells to prevent neurite overlapping were analyzed. Micrographs of fluorescently labeled neurons and neurite arbors were acquired using AxioVision camera and software, and subsequently analyzed using a MATLAB 6.5 script (Gutierrez and Davies, 2007) to generate a Sholl plot.

\section{Production of compartmented neuronal cultures}

Dissociated SMG neurons were plated in the central chambers of compartmented cultures using a previously described protocol (Campenot et al., 2009). Briefly, compartmented cultures were assembled in laminincoated $(10 \mu \mathrm{g} / \mathrm{ml}) 35 \mathrm{~mm}$ Petri dishes using a three-chambered Teflon divider (Tyler Research Corporation) that fluidically isolates neuron cell bodies and proximal axons (PAx) from their distal axons (DAx). The floor of the tissue culture dish was scored into a series of 20 parallel scratches $225 \mu \mathrm{m}$ apart, each of which exposed the bare plastic beneath. Twenty-four hours after the plating of neurons, 3-4 ml of L-15 culture medium with NGF $(50 \mathrm{ng} / \mathrm{ml})$ and cytosine arabinoside $(1 \mu \mathrm{M})$ was added to the perimeter of the PAx compartment. Medium was removed from the DAx compartments and replaced with fresh medium containing NGF (50 ng/ml) plus IL-17 or spleen cell supernatants, or supernatants plus neutralizing antiserum.

Axonal growth into DAx compartments was measured after $5 \mathrm{~d}$ in culture. Axons were fluorescently labeled with calcein-AM $(1 \mu \mathrm{M})$ and visualized using the $20 \times$ objective of an inverted fluorescence microscope (Zeiss Axiovert). An ocular micrometer was used to measure the distance from the edge of the silicone grease barrier to the tip of the longest axon in a track. A minimum of 10 tracks per culture were quantified.

\section{Collection of supernatant from activated splenocytes}

Spleens were isolated from normal mice and quickly transferred to a vial of chilled RPMI-1640 medium (Invitrogen). Spleens were passed through a $70 \mu \mathrm{m}$ pore-size mesh cell strainer (Fisher Scientific) and centrifuged at $400 \times g$ for $10 \mathrm{~min}$. Following removal of supernatant, the red blood cells were lysed (RBC Lysis Buffer) and splenocytes were centrifuged at $400 \times g$ for $10 \mathrm{~min}$. The supernatant was discarded and the cell pellet resuspended in RPMI supplemented with 10\% FBS and $5000 \mathrm{IU}$ penicillin and streptomycin. Viable cells were identified by a trypan blue dye exclusion assay, counted using a hemocytometer and plated at $5 \times$ $10^{6}$ cells/well in a 24 -well tissue culture plate. To stimulate release of cytokines of the adaptive immune system, cells were cultured in the presence of the T-lymphocyte mitogen concanavalin A (ConA, $2.5 \mathrm{~g} / \mathrm{ml}$ ) (Gantner et al., 1995; Palacios, 1982; Sharon and Lis, 1989) for $72 \mathrm{~h}$, at which point cell-free supernatants were harvested and stored at $-20^{\circ} \mathrm{C}$ for subsequent assay. Distal axons of SMG neurons in compartmented cultures were incubated in DAx medium containing either supernatant from ConA-stimulated spleen cells or RPMI with ConA $(2.5 \mu \mathrm{g} / \mathrm{ml})$, NGF, FBS, penicillin, and streptomycin as a vehicle control, at a final dilution of $1: 6$ for $5 \mathrm{~d}$.

\section{ELISA measurement of IL-17}

IL-17 content of activated spleen cell supernatants was determined using a mouse IL-17 sandwich ELISA kit (R \& D Systems), according to the manufacturer's instructions. Samples and standards were assayed in duplicate.

\section{Patch-clamp electrophysiology}

Dissociated SMG neurons were cultured overnight in the presence or absence of IL-17 (1 ng/ml) and/or other drugs. All electrophysiological recordings were performed at room temperature. To record current through voltage-gated $\mathrm{Ca}^{2+}$ channels $\left(I_{\mathrm{Ca}}\right.$; carried by $\left.\mathrm{Ba}^{2+}\right)$, coverslips of dissociated neurons were superfused with an external solution of the following composition (mM): 140 tetraethylammonium (TEA)-Cl, $2 \mathrm{MgCl}_{2}, 5 \mathrm{BaCl}_{2}, 10$ glucose, 10 HEPES ( $\mathrm{pH} 7.4$ with TEA$\mathrm{OH})$. Fire-polished glass pipettes with resistances between 3 and $8 \mathrm{M} \Omega$ were back-filled with internal solution containing the following (in $\mathrm{mM}$ ): $120 \mathrm{CsCl}, 1 \mathrm{MgCl}_{2}, 4 \mathrm{MgATP}, 0.3 \mathrm{NaGTP}, 10$ EGTA, 10 HEPES, and 50 $\mu \mathrm{g} / \mathrm{ml}$ amphotericin $\mathrm{B}$ ( $\mathrm{pH} 7.2$ with $\mathrm{CsOH}$ ). Patch pipettes were lowered onto cells visualized with a phase contrast microscope, and once a seal was established (1 G $\Omega$ or greater) and perforation had taken place (access resistance $<20 \mathrm{M} \Omega$ ), series resistance was compensated at least $80 \%$. Data were acquired using a Digidata 1440A analog-to-digital converter and pClamp 10.1 software (MDS Analytical Technologies). Current recordings were normalized to cell capacitance and expressed as current density.

\section{$\mathrm{Ca}^{2+}$ imaging}

Dissociated SMG neurons were incubated with the fluorescent $\mathrm{Ca}^{2+}$ indicator dye Fura-2 AM $(5 \mu \mathrm{M})$ for $30-45 \mathrm{~min}$ at $37^{\circ} \mathrm{C}$. Cells were washed three times and left to cool to room temperature in HEPES buffer [containing the following (in mM): $140 \mathrm{NaCl}, 5 \mathrm{KCl}, 2 \mathrm{CaCl}_{2}, 1 \mathrm{MgCl}_{2}, 10$ HEPES, 10 glucose, $\mathrm{pH}$ adjusted to 7.4 with $\mathrm{NaOH}$ ] for 20-30 min before imaging to remove extracellular dye and allow for intracellular deesterification of the Fura. Coverslips were continuously superfused with the HEPES-buffered solution throughout the experiment. ROI were defined either within the cell body of the neuron or within the growth cone for experiments on Day 2. Growth cones were identified visually by their fan-like morphology (Ibarretxe et al., 2007). The cells were illuminated at 340 and $380 \mathrm{~nm}$ once per second using a DeltaRamV high-speed random access monochrometer (Photon Technology International). Images were recorded using a Photometrics Cascade 512B CCD camera and ImageMaster 5.0 software. The ratio of fluorescence at $340 \mathrm{~nm}$ (f340) versus $380 \mathrm{~nm}$ (f380) excitation within ROI was calculated and used to estimate $\left[\mathrm{Ca}^{2+}\right]_{\mathrm{i}}$. The amplitude of depolarization-induced $\mathrm{Ca}^{2+}$ entry, evoked by superfusion of high $\mathrm{K}^{+}$external solution of the following composition (mM): $105 \mathrm{NaCl}, 40 \mathrm{KCl}, 2 \mathrm{CaCl}_{2}, 1 \mathrm{MgCl}_{2}, 10$ HEPES, 10 glucose, $\mathrm{pH}$ adjusted to 7.4 with $\mathrm{NaOH}$, was compared in control cells and cells cultured in IL-17.

\section{Data analysis}

All morphological analyses were performed by observers blind to the treatment groups. Current-voltage relationships were analyzed using Clampfit, Version 10 (MDS Analytical Technologies). Statistical analyses were performed and graphs were generated using GraphPad Prism 5 software. Population data were analyzed by Mann-Whitney or KruskalWallis tests followed by Dunn's multiple comparison posttests for nonparametric data. A two-way ANOVA was used when analyzing current-voltage relationships and Sholl plots, with Bonferroni's post hoc test to determine significant differences between the group means. Population data are presented as means \pm SEM. Statistical significance was reached at $p<0.05$.

\section{Results}

\section{Sympathetic neurons express the receptor for IL-17}

IL-17 receptor immunoreactivity was localized to the somata of sympathetic neurons in sections of mouse SMG (Fig. 1A). Ninetyfive $\pm 2 \%$ of TH-IR SMG neurons were immunoreactive for IL-17R, and $84 \pm 3 \%$ of IL-17R-immunoreactive cells were TH-IR ( $n=6$ mice for each count). Furthermore, isolated SMG neurons cultured for $3 \mathrm{~d}$ exhibited IL-17R expression within the soma and along neurites (Fig. $1 B$ ). 

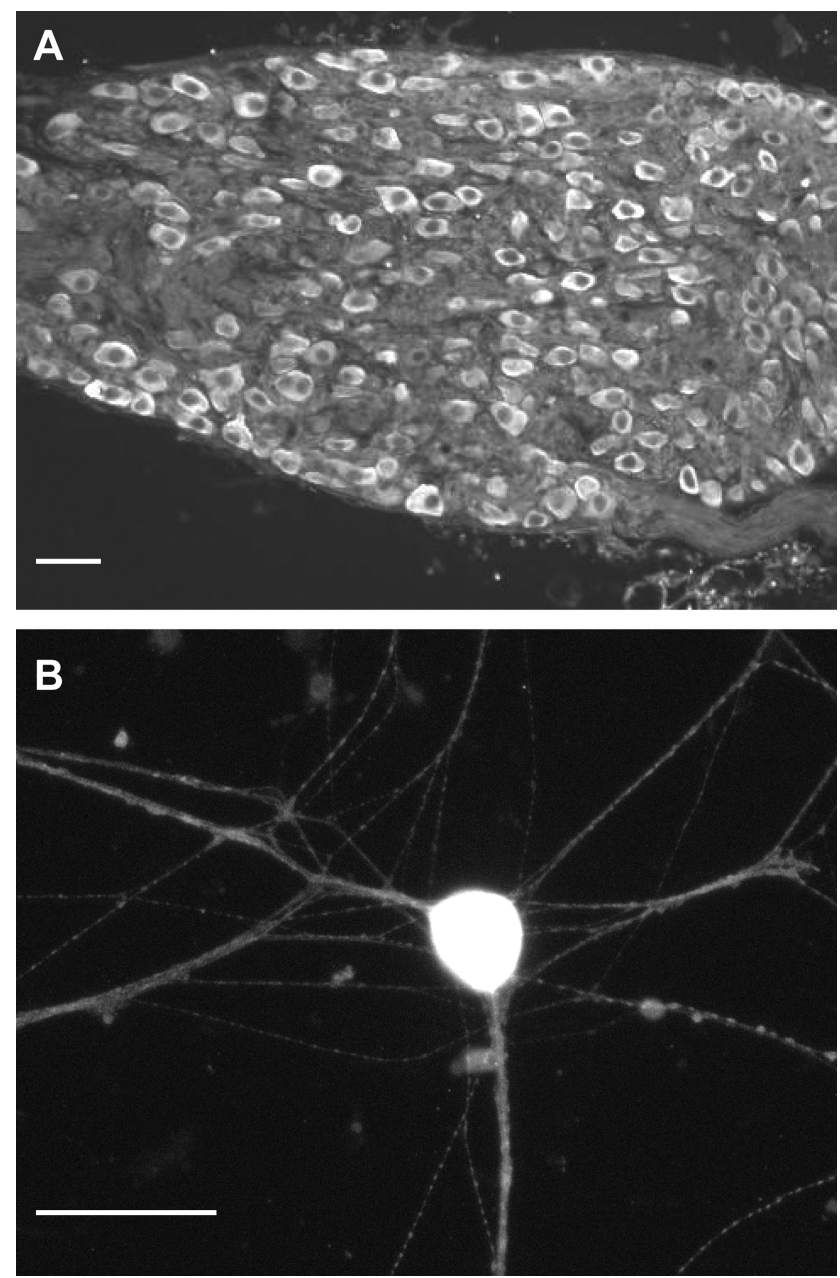

Figure 1. Neurons from SMG express the receptor for IL-17. A, Immunofluorescent labeling of cryostat sections of SMG revealed abundant IL-17 receptor expression within neuronal perikarya. Receptor immunoreactivity was also observed in cultured SMG neurons $\boldsymbol{B}, \mathrm{IL}-17$ receptor expression was localized to cell bodies, neurites, and growth cones. Scale bars, $50 \mu \mathrm{m}$.

Supernatant from activated T lymphocytes evokes neurite outgrowth that is inhibited by neutralization of IL-17

Neurons within the SMG project axons to the spleen, where they are thought to play an immunomodulatory role (Rosas-Ballina et al., 2011). We therefore determined the effect of exposing SMG neurons to the inflammatory mediators released from activated splenocytes. In vitro restimulation of isolated spleen cells by ConA induces polyclonal $\mathrm{T}$ cell differentiation, leading to the release of cytokine mediators of the adaptive immune response (Palacios, 1982; Schulz et al., 2008). We incubated distal SMG neurites in supernatant obtained from activated $\mathrm{T}$ lymphocytes for $5 \mathrm{~d}$ and measured neurite extension in compartmented cultures. Sympathetic neurites exposed to the supernatant were significantly longer than neurites incubated in the vehicle control (Fig. 2). Undiluted supernatant collected from activated T lymphocytes contained a high concentration of IL-17 (48.32 \pm 14.41 $\mathrm{ng} / \mathrm{ml}, n=5$ supernatants from 5 mice), as determined by ELISA. Given a 1:6 dilution of the supernatant in media, the final concentration of IL-17 in the media was $\sim 8 \mathrm{ng} / \mathrm{ml}$. Neutralization of IL-17 activity by addition of an IL-17 function-blocking antibody [2.5 $\mu \mathrm{g} / \mathrm{ml}$, a concentration previously reported to block IL-17 signaling (Yao et al., 1995a,b); R \& D Systems] blocked neurite outgrowth in response to splenocyte supernatant (Fig. 2). Splenocyte supernatant still exerted a significant neurotrophic

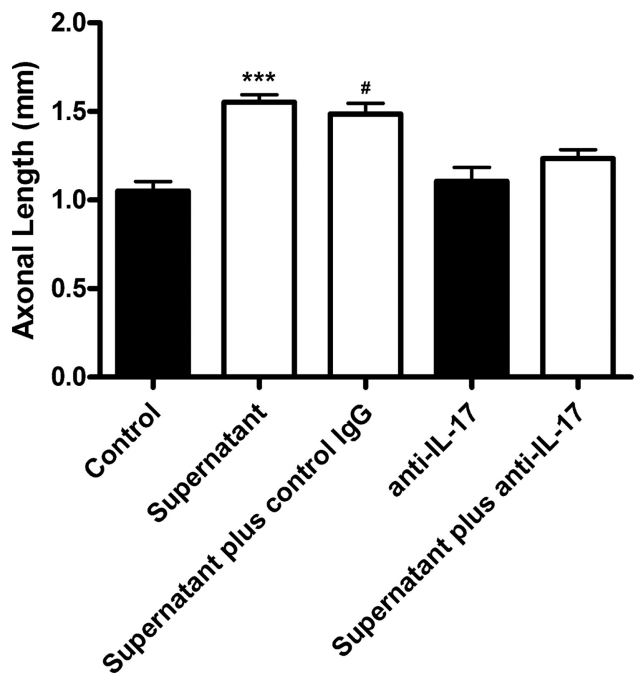

Figure 2. Supernatants from cultured splenocytes exerted an IL-17-dependent neurotrophic effect on SMG neurons. Concanavalin A-stimulated splenocyte supernatant was added to distal compartments of SMG neurons in compartmented cultures and markedly enhanced levels of neurite extension relative to neurites cultured in the vehicle control for $5 \mathrm{~d}$. Blocking IL-17 activity with a neutralizing antibody had no effect on neurite outgrowth when added alone but eliminated the ability of splenocyte supernatants to promote sympathetic axon outgrowth. An isotype-matched control antiserum did not block the neurotrophic effect of splenocyte supernatant. $N>40$ lanes per treatment group. ${ }^{* * *} p<0.0001$ versus all other treatment groups except for supernatant plus control lgG; ${ }^{\#} p<0.05$ versus all other treatment groups except for supernatant; Kruskal-Wallis test with Dunn's multiple comparison posttest.

effect on neurites cultured in the presence of an isotype control IgG (Abcam) relative to control cultures.

Interleukin-17 enhances neurite outgrowth and arborization We next investigated whether IL-17 could induce sympathetic axon remodeling using several in vitro assays of neurite outgrowth (Fig. 3). The ratio of neurites to neurons was significantly increased among neurons exposed to recombinant mouse IL-17 ( $1 \mathrm{ng} / \mathrm{ml}$ ) compared with control neurons at Days 2 and 3. Incubation in IL-17 did not have any effect on the number of neurons, identified by $\mathrm{HuD}$ immunoreactivity (control: $211 \pm 58$ neurons per coverslip, $n=8$; IL-17: $190 \pm 89$ neurons per coverslip, $n=$ $7 ; p>0.05$, Mann-Whitney test). Similarly, the number of glial cells per coverslip (identified by SOX-10 immunoreactivity) was not affected by incubation in IL-17 for $7 \mathrm{~d}$ (control: $5116 \pm 975$ cells, $n=5$; IL-17: $4677 \pm 266$ cells, $n=5$; $p>0.05$, MannWhitney test). These data indicate that IL-17 does not affect neuronal or glial survival. Sholl analysis of neurite arborization was performed on neurons cultured for $5 \mathrm{~d}$ in the presence or absence of IL-17. This time point was chosen to allow significant neurite outgrowth without resulting in overlap between the neurites of adjacent neurons. Sholl analysis demonstrated that neurons incubated in IL-17 had increased morphological complexity relative to control neurons (Fig. 3D). The number of intersections between neurites and a series of concentric rings superimposed on the neural soma were statistically increased between 75 and $210 \mu \mathrm{m}$ from the cell body in IL-17-treated cultures compared with control cultures.

Enhanced neurite growth does not depend on glial cells Glial cells present in the SMG cultures may mediate the effect of IL-17 on SMG neurite outgrowth. To create enriched neuronal cultures with little to no glia, $5 \mu \mathrm{m}$ cytosine arabinoside (AraC) (Besirli et al., 2003) was added after $24 \mathrm{~h}$ of culture. AraC depleted 
SOX-10-immunoreactive glia by $65 \pm$ $7 \%$ at Day 3 and $89 \pm 2 \%$ at Day $7(n=$ 4 coverslips for control, 6 for IL-17). IL-17 significantly increased the number of neurites per neuron at Days 2, 3, and 7 in the presence of AraC (Fig. 4) to an extent that was not different from IL-17 alone.

Inhibition of $\mathrm{Ca}^{2+}$ currents by IL-17 An important mechanism of neurite outgrowth regulation is the control of intracellular $\left[\mathrm{Ca}^{2+}\right]$ (Bolsover, 2005; Spitzer, 2006). Electrophysiological and $\mathrm{Ca}^{2+}$ imaging studies were therefore undertaken to determine whether IL-17 caused alterations in $I_{\mathrm{Ca}}$. Overnight incubation with IL-17 significantly attenuated inward voltage-gated $\mathrm{Ca}^{2+}$ current, as measured by voltageclamp electrophysiology (Fig. 5A,B). Intracellular $\mathrm{Ca}^{2+}$ imaging in both the cell bodies (Fig. 5C) and growth cones (Fig. 5D) revealed that the peak f340:f380 increase as a percentage of baseline during depolarization with $40 \mathrm{~mm}$ extracellular $\mathrm{K}^{+}$was significantly lower in neurons cultured overnight in the presence of IL-17.

\section{Attenuating $I_{\mathrm{Ca}}$ causes enhanced growth}

If $I_{\mathrm{Ca}}$ inhibition is involved in the neurite growth induced by IL-17, then the effects of IL-17 on neurite outgrowth should be replicated by an $I_{\mathrm{Ca}}$ blocker. To inhibit inward $I_{\mathrm{Ca}}$, we chose a concentration of $\omega$-conotoxin GVIA (30 nM) that would partly block the current through the N-type VGCC, which is the predominant type of VGCC in SMG neurons (Motagally et al., $2009 a, b)$. Incubation of SMG neurons for up to $3 \mathrm{~d}$ recapitulated the enhanced neurite outgrowth seen with IL-17 treatment (Fig. 5E).

\section{Electrophysiological and neurotrophic effects of IL-17 are reversed by an NF- $\kappa \mathrm{B}$ inhibitor}

The NF- $\kappa$ B intracellular signaling pathway plays a key role in the induction of many inflammatory signaling cascades (Shen and Gaffen, 2008). Using SC-514, which blocks the I $\kappa$ kinase activation and subsequent activity in the NF- $\kappa \mathrm{B}$ signaling cascade, we investigated whether the effects of IL-17 on $I_{\mathrm{Ca}}$ and neurite outgrowth were dependent on NF- $\kappa$ B signaling. Preincubation of cultured neurons in SC-514 $(20 \mu \mathrm{M}) 2 \mathrm{~h}$ before addition of IL-17, and throughout incubation with IL-17, almost completely prevented $I_{\mathrm{Ca}}$ inhibition by IL-17 (Fig. 6A). We have previously shown that SC-514 alone has no effect on $I_{\mathrm{Ca}}$ (Motagally et al., 2009a), suggesting that the effect of SC-514 was on intracellular signaling downstream of IL1-7 receptor activation, rather than a direct effect on $I_{\mathrm{Ca}}$. Consistent with these voltage-clamp data, $\mathrm{Ca}^{2+}$ imaging analysis showed that cultures pretreated with SC514 before IL-17 had significantly larger increases in f340:f380 compared with IL-17 treatment alone (data not shown). Importantly, inhibition of NF- $\kappa$ B also mitigated the effects of IL-17 on neurite outgrowth (Fig. 6B).

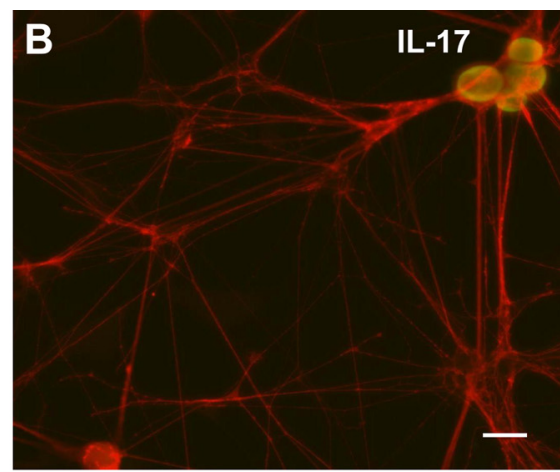

D

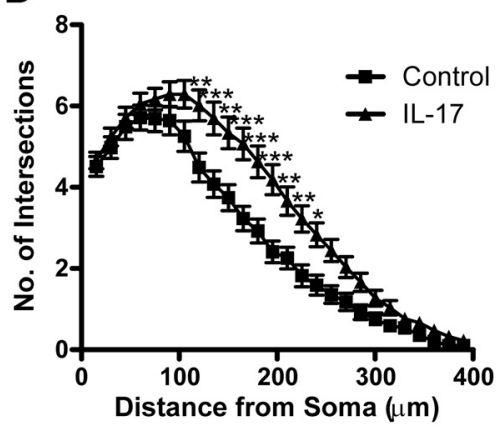

Figure 3. IL-17 enhanced neurite outgrowth and branching. $\boldsymbol{A}, \boldsymbol{B}$, Representative images of control $(\boldsymbol{A})$ and IL-17 (1 ng/ml)-treated ( $\boldsymbol{B})$ neurons incubated in IL-17 compared with controls. $N=40-60$ neurons per treatment group. ${ }^{*} p<0.05 ;{ }^{* *} p<0.01 ;{ }^{* * *} p<0.001$ two-way ANOVA with Bonferroni's posttest.

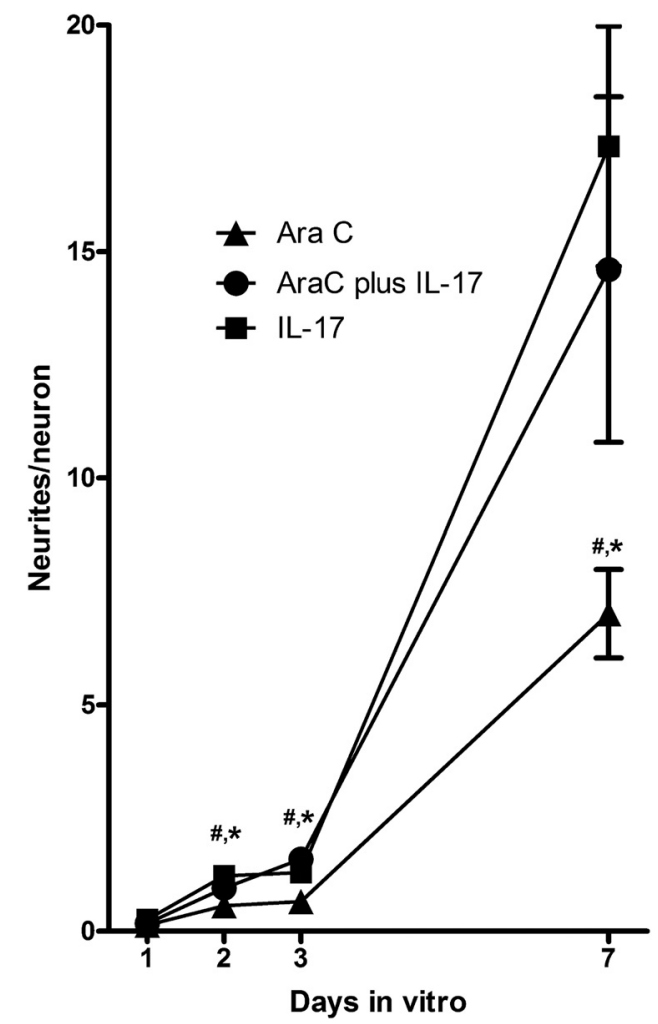

Figure 4. Neurotrophic effects of IL-17 did not depend on glial cells. When the glial cell population was depleted with $\operatorname{AraC}(5 \mu \mathrm{m})$, IL-17 still significantly enhanced the number of neurites per neuron after 3 and 7 d in culture. $N=$ at least 6 coverslips per treatment group, ${ }^{*} p<0.05$ AraC versus AraC plus IL-17; ${ }^{\#} p<0.05$ AraC versus IL-17; Kruskal-Wallis test with Dunn's multiple comparison posttest. 
A
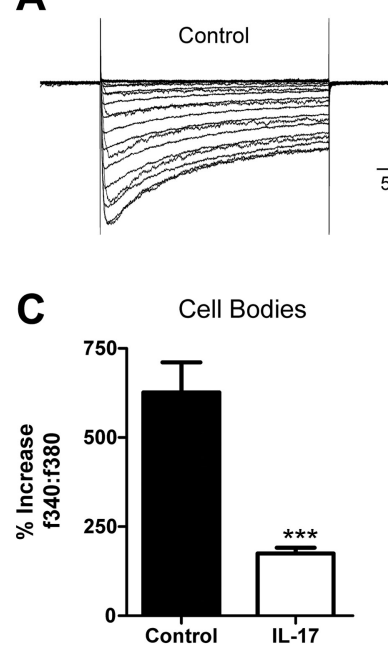

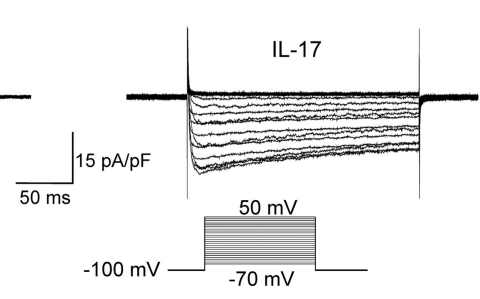

D

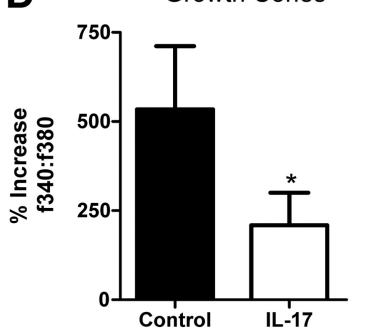

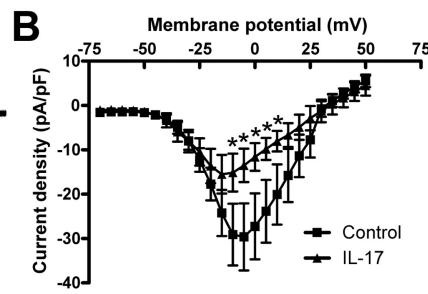

E

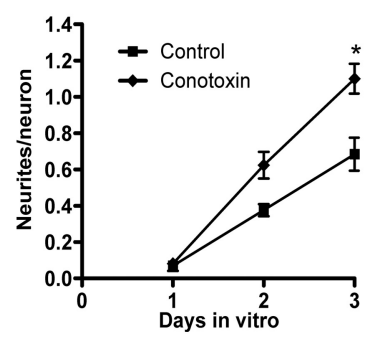

Figure 5. IL-17 inhibited voltage-gated $\mathrm{Ca}^{2+}$ current. $A$, Representative voltage-clamp recordings of $I_{\mathrm{Ca}}$ from a control neuron and a neuron incubated in IL-17 overnight. The voltage-clamp protocol is illustrated in inset. $\boldsymbol{B}$, Mean $\pm S E M$ current voltage relations of control and IL-17-treated neurons. Incubation of neurons in $1 \mathrm{ng} / \mathrm{ml} I \mathrm{LL}-17$ significantly reduced $I_{\mathrm{Ca}}$ between -10 and 10 $\mathrm{mV} . \mathrm{N}=21$ control cells, $13 \mathrm{IL}-17 ;{ }^{*} p<0.05$, two-way ANOVA with Bonferroni's posttest. $\mathrm{C}_{,} \mathrm{Ca}^{2+}$-imaging data demonstrate a significant decrease in the peak intracellular $\mathrm{Ca}^{2+}$ transient during a $40 \mathrm{~mm} \mathrm{KCl-induced} \mathrm{depolarization} \mathrm{in} \mathrm{neurons} \mathrm{incubated} \mathrm{in} \mathrm{IL-17} \mathrm{compared} \mathrm{with} \mathrm{controls.} N=34$ cells per treatment group; ${ }^{* * *} p<0.0001$, Mann-Whitney test. $\boldsymbol{D}$, IL-17 significantly attenuated depolarization-induced $\mathrm{Ca}^{2+}$ influx in SMG neuronal growth cones. $N=8$ cells for control, 10 cells for IL-17; ${ }^{*} p<0.05$, Mann-Whitney test. $\boldsymbol{E}$, Treatment of SMG neurons with the N-type Ca ${ }^{2+}$ channel blocker $\omega$-conotoxin GVIA ( $30 \mathrm{~nm})$ significantly enhanced the ratio of neurites to neurons compared with controls. ${ }^{*} p<0.05$ relative to control; two-way ANOVA with Bonferroni's post hoc test; $N=6$ coverslips per treatment group.
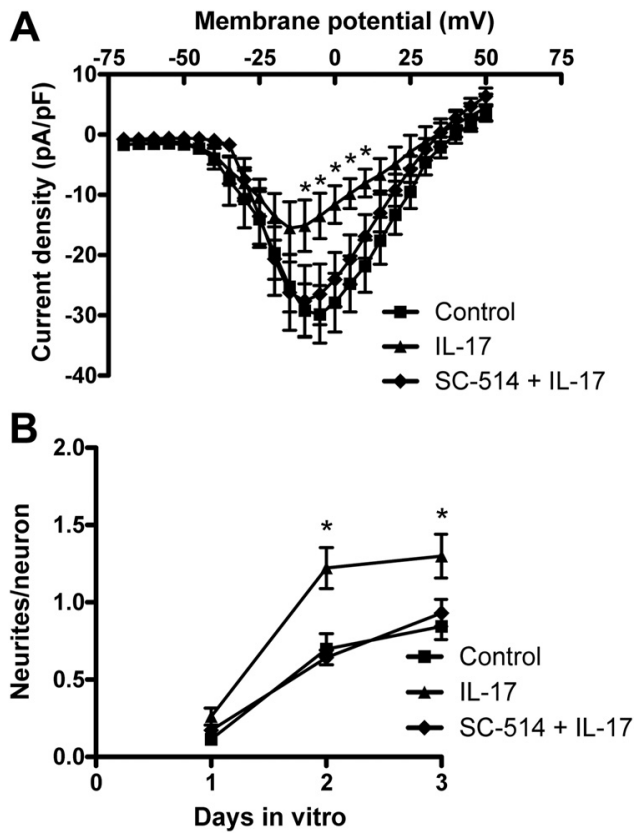

Figure 6. Inhibition of NF- $\kappa B$ signaling blocked the effects of $I L-17$ on $I_{C a}$ and neurite outgrowth. $A$, Current voltage curve depicting the effect of blocking the NF- $\kappa B$ pathway on $I_{\text {Ca }}$ inhibition by IL-17. With SC-514 pretreatment, control and experimental values were not significantly different $(N=21$ for control, 13 for IL-17, 12 for SC $-514 ; p>0.05$ between control and SC-514, two-way ANOVA; $p<0.05$ between control and IL- 17 from -10 to $+10 \mathrm{mV}$; Fig. 4). $\boldsymbol{B}$, Pretreatment with SC-514 prevented the enhanced neurite outgrowth caused by IL-17. In SC-514-treated coverslips, the ratio of neurites to neurons in the presence of IL-17 was not significantly different from control ( ${ }^{*} p>0.05$, Mann-Whitney test).

\section{IL-17 is chemotactic for extending neurites}

Using SMG explants seeded onto collagen gels, the growth of neurites toward an IL-17 (100 ng/ml)-soaked agarose bead was examined. Directional growth toward the cytokine-soaked bead was significantly increased relative to an HBSS-soaked negative control bead (Fig. 7A-C). In addition, we used the compartmented culture system to further localize the effects of IL-17 on SMG neurite proliferation by selectively applying the cytokine to cell bodies and PAx or DAx for $5 \mathrm{~d}$ (Fig. 7D). Addition of IL-17 to either the PAx or DAx compartments resulted in significantly increased axonal outgrowth relative to control cultures. Interestingly, selective application of IL-17 to distal terminals significantly enhanced axonal length relative to neurons exposed to the cytokine in the cell body compartment.

\section{Discussion}

The $\mathrm{T}_{\mathrm{H}} 17$ lineage of $\mathrm{T}$ lymphocytes is increasingly recognized as playing a central role in autoimmune diseases that are accompanied by neuronal dysfunction, including IBD, rheumatoid arthritis, and multiple sclerosis (MS). An elegant study of the experimental autoimmune encephalitis model of MS in mice found compelling evidence of a contribution of $T_{H} 17$ lymphocytes to neuronal dysfunction within brainstem plaques (Siffrin et al., 2010). IL-17 is the canonical cytokine released from $\mathrm{T}_{\mathrm{H}} 17$ lymphocytes, yet little was known before the current study about its effects on neurons. Our findings identify a novel role for IL-17 in increasing neurite outgrowth from adult sympathetic postganglionic neurons by activation of NF- $\kappa \mathrm{B}$ signaling and suppression of voltage-dependent $\mathrm{Ca}^{2+}$ influx.

IL-17-secreting immune cells contribute to the pathogenesis of inflammatory disease by amplifying effector immune responses that ultimately give rise to tissue damage (Langrish et al., 2005; Park et al., 2005; Yen et al., 2006; Siffrin et al., 2010). In contrast to these damaging effects, supernatant from activated T cells had significant neurotrophic effects when applied to the axons of SMG neurons. A neutralizing antibody that blocked IL-17 function (Yao et al., 1995a,b) abolished axon extension in the presence of $\mathrm{T}$ lymphocyte supernatants. This is consistent with a recent study of corneal nerve regeneration following corneal abrasion, where restoration of sub-basal nerve plexus density was attenuated by $>50 \%$ following systemic treatment with 
an IL-17 function-blocking antibody (Li et al., 2011). However, the neurotrophic effects of IL-17 in the cornea were attributed to the arrival of trophic factorsecreting neutrophils at the wound site, whereas our data suggest that IL-17 can exert a direct neurotrophic effect on SMG neurons. Thus, our current findings, along with those of Li et al. (2011), suggest that IL-17 can participate in neural tissue remodeling and repair via direct or indirect signaling mechanisms.

\section{Mechanisms of IL-17 effects on SMG neurons}

The link between $\mathrm{Ca}^{2+}$ influx and regulation of neurite outgrowth is well established (Bolsover, 2005; Spitzer, 2006), and it appears that in many systems, a rise in $\left[\mathrm{Ca}^{2+}\right]_{\mathrm{i}}$ precludes neurite sprouting. A recent study of Xenopus motor neurons implicated N-type VGCCs in the ability of the growing neurite to transduce a stop signal upon encountering the appropriate target extracellular matrix (Sann et al., 2008). Similarly, Ryan et al. (2007) demonstrated that depolarization inhibits neurite outgrowth from descending lamprey brain neurons, and that this inhibition is due to inward current through $\mathrm{N}$-type VGCCs. Consistent with these findings, incubation of SMG neurons in IL-17 inhibited $\mathrm{Ca}^{2+}$ currents through VGCCs in cell bodies and growth cones. Interestingly, incubation of SMG neurons with $\omega$-conotoxin-GVIA increased the growth of neurites to a level similar to that seen following IL-17 incubation. These data suggest that inhibition of VGCC may contribute to neurite outgrowth from SMG neurons in response to IL-17. VGCC inhibition alone is not sufficient to explain how IL-17 promotes neurite outgrowth from adult SMG neurons, because TNF $\alpha$ also inhibits VGCC in these neurons (Motagally et al., 2009a) but has no impact on neurite outgrowth (data not shown). However, TNF $\alpha$ has inconsistent effects on $\mathrm{Ca}^{2+}$ influx and neurite outgrowth in postganglionic sympathetic neurons. In contrast to adult SMG neurons, VGCC is enhanced by TNF $\alpha$ in neonatal superior cervical ganglion (Soliven and Albert, 1992), a population of neurons whose neurite outgrowth is inhibited by TNF $\alpha$ (Gutierrez et al., 2008). These inconsistencies may be related to the differences in growth responses between adult and neonatal neurons or the status of NF- $\kappa \mathrm{B}$ signaling. Nonetheless, it is noteworthy that, similar to the effect of IL-17 on adult SMG neurons, sympathetic neurite outgrowth from neonatal SCG neurons in response to TNF $\alpha$ is associated with changes in $\mathrm{Ca}^{2+}$ influx pathways.

Inhibition of the NF- $\kappa$ B pathway prevented both the IL-17induced neurite outgrowth and alterations in $I_{\mathrm{Ca}}$. These data suggest mechanistic commonality between the two effects of IL-17. Although IL-17 may inhibit inward $\mathrm{Ca}^{2+}$ current and enhance neurite growth through separate pathways downstream of $\mathrm{NF}-\kappa \mathrm{B}$ activation, the likeliest explanation for these results is that

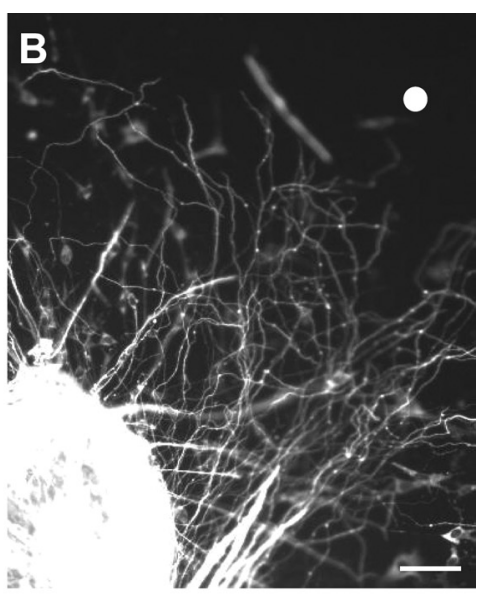

D

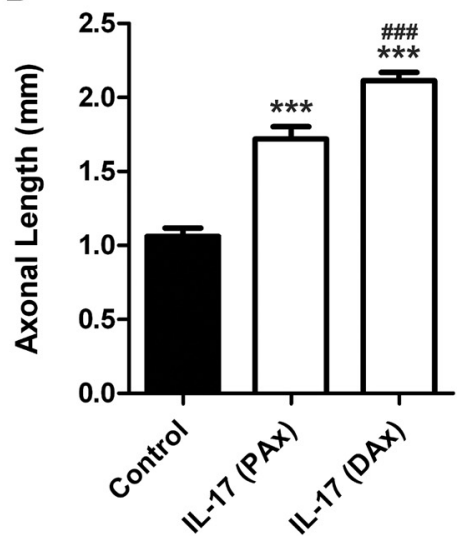

Figure 7. Neurites of SMG neurons grew preferentially toward sources of IL-17. Analysis of $\beta 3$-tubulin immunoreactivity in SMG explants cultures revealed enhanced neurite outgrowth in the direction of an IL-17-soaked bead relative to control ( $N=5$ per Bead location is marked with a circle on the representative micrographs. $\boldsymbol{A}, \boldsymbol{B}$, Control (HBSS-soaked) bead (A) and IL-17 (1) Scale bars, $25 \mu \mathrm{m}$. C, Mean \pm SEM ratio of fluorescence from regions of interest in the quadrant 0 e micrograph closest to the bead relative to the quadrant on the opposite side of the micrograph (opposite quadrants not shown ( significantly enhanced axonal extension after $5 \mathrm{~d}$ relative to neurons cultured in control medium and neurons exposed to the cytokine in the cell body compartment $\left({ }^{* * *} p<0.0001\right.$ vs control; ${ }^{\# \# \#} p<0.0001$ vs PAx; Kruskal-Wallis test with Dunn's multiple vomparison posttest; $N>30$ lanes per treatment).

NF- $\kappa \mathrm{B}$-dependent regulation of neurite outgrowth and $\mathrm{Ca}^{2+}$ signaling are interrelated. We propose a model wherein NF- $\kappa \mathrm{B}-$ dependent inhibition of N-type VGCC relieves a constitutive stop signal and results in increased growth and elaboration of sympathetic neurites. The involvement of NF- $\kappa \mathrm{B}$ signaling in regulating neurite outgrowth is consistent with reports on neonatal neurons from cortex, nodose ganglion, and superior cervical ganglion (Gutierrez et al., 2005, 2008; Gutierrez and Davies, 2011) and suggests an important role for this intracellular signaling network in neuroanatomical plasticity that extends beyond the developing nervous system.

Certain cytokines (IL-4, IL-6, and interferon- $\gamma$ ) enhance the growth of neurites initiated by endogenous and recombinant neurotrophins (Gölz et al., 2006; O’Keeffe et al., 2008). NGF was present in all culture media, as postganglionic neurons cannot survive without it. Therefore, it is possible that IL-17 is acting synergistically by enhancing the actions of NGF. We examined this possibility using real-time reverse transcription PCR to quantify mRNA encoding TrkA and p75 receptors for NGF. Overnight incubation of SMG neurons with IL-17 had no effect on TrkA or p75 expression (data not shown). Furthermore, since 
inhibition of NF- $\kappa$ B reversed the effect of IL-17, and NGF does not predominantly act via this pathway (Neet and Campenot, 2001), it is plausible that IL-17 enhances neurite outgrowth via a novel mechanism that may or may not overlap with NGF signaling. However, structural homologies between NGF and IL-17 dimers exist in locations corresponding to receptor-binding domains (Hymowitz et al., 2001), suggesting similar receptorligand signaling properties between the two molecules. NGFmediated neuronal survival is dependent on retrograde axonal signaling pathways following NGF binding to cognate receptors on distal axon terminals, though the mechanistic nature of this signal remains to be fully understood (Neet and Campenot, 2001; Barker et al., 2002). In a similar fashion, IL-17 acting at distal sympathetic terminals may support axonal growth by retrograde transport mechanisms that involve downstream activation of $\mathrm{NF}-\kappa \mathrm{B}$ at the neuronal cell body. Additional studies will be required to fully characterize the precise molecular events mediating IL-17-induced changes in sympathetic axon architecture.

\section{IL-17 can act directly on sympathetic axons to drive outgrowth}

Evidence from the current study suggests that IL-17 can act directly on SMG neurons, rather than glial cells, to drive neurite elongation in vitro. The receptor for IL-17 is localized to THimmunoreactive neuronal cell bodies and neurites. The effects of IL-17 on SMG neurite growth in vitro were most pronounced when IL-17 was applied selectively to distal axons in the complete absence of glia. Furthermore, the directional outgrowth of sympathetic axons in explant cultures toward a source of IL-17 is consistent with a direct action of IL-17 on sympathetic axons. Together, these data suggest that, in vivo, sympathetic axons that innervate inflamed tissues may be exposed to elevated levels of IL-17 that can act directly on nerve terminals to drive outgrowth, which may contribute to sympathetic neuroanatomical remodeling during inflammation. However, it is still possible that circulating IL-17 acts in part via glial cells within sympathetic ganglia to enhance axon outgrowth.

\section{Comparison with the conditioning lesion effect}

One of the best characterized examples of cytokine involvement in sympathetic neuroanatomical plasticity is their participation in neurite outgrowth following a conditioning lesion, such as axotomy (McQuarrie and Grafstein, 1973; McQuarrie et al., 1978). The conditioning lesion enhances the expression of cytokines of the gp130 family, which includes leukemia inhibitory factor, IL-6, IL-11, and oncostatin M, in tissues innervated by the axotomized sympathetic neurons and in the sympathetic neurons themselves (Hyatt Sachs et al., 2010). These cytokines then contribute to regeneration of damaged axons following nerve injury. While the enhancement of sympathetic neurite outgrowth by IL-17 is reminiscent of the conditioning response, several observations suggest they are two independent processes. First, IL-17 does not contain the gp130 protein motif, which is a prerequisite for mediators of the conditioning lesion effect on sympathetic neurons (Hyatt Sachs et al., 2010). Second, the conditioning lesion response predominantly uses the janus kinase-signal transducer and activator of transcription 3 pathways (Rajan et al., 1995; Habecker et al., 2009; Hyatt Sachs et al., 2010 ), in contrast to the NF- $\kappa \mathrm{B}$-dependent effect of IL-17. Therefore, we propose that IL-17 mediates a neuroanatomical response distinct from the effect of conditioning lesions.

\section{Interleukin 17, $\mathrm{T}_{\mathrm{H}} 17$ diseases, and neuronal alterations}

The discovery of the $\mathrm{T}_{\mathrm{H}} 17$ lineage of $\mathrm{T}$ helper lymphocytes, defined by their production and secretion of IL-17, has lead to an appreciation of the role that this cytokine plays in several immune-mediated diseases. While the general consensus is that IL-17 is a damaging, proinflammatory cytokine, there is emerging evidence that it plays a role in homeostasis and tissue repair (Littman and Rudensky, 2010). Our findings demonstrate a novel neurotrophic effect of IL-17 on adult sympathetic neurons that appears to be dependent on NF- $\kappa \mathrm{B}$ activation and inhibition of intracellular $\mathrm{Ca}^{2+}$ dynamics. The finding that IL-17 promotes neurite arborization may provide a mechanism for some of the morphological and functional alterations in the SNS that occurs in inflammatory diseases dominated by a $\mathrm{T}_{\mathrm{H}} 17$ cytokine profile. For example, in murine models of arthritis and colitis, both of which are mediated by IL-17-producing CD4 ${ }^{+}$lymphocytes (Murphy et al., 2003; Nakae et al., 2003; Roark et al., 2007), sympathetic innervation density is enhanced (Almarestani et al., 2008). It is also interesting to consider these findings in the context of recent reports of sympathetic suppression of the innate immune response (Rosas-Ballina et al., 2008; Vida et al., 2011) and enhancement of IL-17 secretion from T lymphocytes (Kim and Jones, 2010; Manni et al., 2011). If IL-17 does attract axons toward a cellular source of IL-17, it may create a positive feedback loop that drives further IL-17 secretion. Together, our findings identify IL-17 as a potentially important mediator of sympathetic neuroanatomical plasticity during inflammation and emphasize that sympathetic axons are not static entities, but rather dynamic structures capable of adaptive responses to changes in immune system activation.

\section{References}

Almarestani L, Longo G, Ribeiro-da-Silva A (2008) Autonomic fiber sprouting in the skin in chronic inflammation. Mol Pain 4:56.

Antunes NL, Khakoo Y, Matthay KK, Seeger RC, Stram DO, Gerstner E, Abrey LE, Dalmau J (2000) Antineuronal antibodies in patients with neuroblastoma and paraneoplastic opsoclonus-myoclonus. J Pediatr Hematol Oncol 22:315-320.

Barker PA, Hussain NK, McPherson PS (2002) Retrograde signaling by the neurotrophins follows a well-worn trk. Trends Neurosci 25:379-381.

Barrett JM, Mangold KA, Jilling T, Kaul KL (2005) Bi-directional interactions of prostate cancer cells and bone marrow endothelial cells in threedimensional culture. Prostate 64:75-82.

Besirli CG, Deckwerth TL, Crowder RJ, Freeman RS, Johnson EM Jr (2003) Cytosine arabinoside rapidly activates Bax-dependent apoptosis and a delayed Bax-independent death pathway in sympathetic neurons. Cell Death Differ 10:1045-1058.

Bettelli E, Korn T, Kuchroo VK (2007) Th17: the third member of the effector T cell trilogy. Curr Opin Immunol 19:652-657.

Birch D, Knight GE, Boulos PB, Burnstock G (2008) Analysis of innervation of human mesenteric vessels in non-inflamed and inflamed bowel: a confocal and functional study. Neurogastroenterol Motil 20:660-670.

Bolsover SR (2005) Calcium signalling in growth cone migration. Cell Calcium 37:395-402.

Campenot RB, Lund K, Mok SA (2009) Production of compartmented cultures of rat sympathetic neurons. Nat Protoc 4:1869-1887.

Eisenhofer G, Friberg P, Rundqvist B, Quyyumi AA, Lambert G, Kaye DM, Kopin IJ, Goldstein DS, Esler MD (1996) Cardiac sympathetic nerve function in congestive heart failure. Circulation 93:1667-1676.

Gantner F, Leist M, Lohse AW, Germann PG, Tiegs G (1995) Concanavalin A-induced T-cell-mediated hepatic injury in mice: the role of tumor necrosis factor. Hepatology 21:190-198.

Geddes JW, Wilson MC, Miller FD, Cotman CW (1990) Molecular markers of reactive plasticity. Adv Exp Med Biol 268:425-432.

Ghia JE, Blennerhassett P, Collins SM (2008) Impaired parasympathetic function increases susceptibility to inflammatory bowel disease in a mouse model of depression. J Clin Invest 118:2209-2218.

Gibbs GF, Drummond PD, Finch PM, Phillips JK (2008) Unravelling the 
pathophysiology of complex regional pain syndrome: focus on sympathetically maintained pain. Clin Exp Pharmacol Physiol 35:717-724.

Gölz G, Uhlmann L, Lüdecke D, Markgraf N, Nitsch R, Hendrix S (2006) The cytokine/neurotrophin axis in peripheral axon outgrowth. Eur J Neurosci 24:2721-2730.

Graham RM, Friedman M, Hoyle GW (2001) Sensory nerves promote ozone-induced lung inflammation in mice. Am J Respir Crit Care Med 164:307-313.

Gutierrez H, Davies AM (2007) A fast and accurate procedure for deriving the Sholl profile in quantitative studies of neuronal morphology. J Neurosci Methods 163:24-30.

Gutierrez H, Davies AM (2011) Regulation of neural process growth, elaboration and structural plasticity by NF-kappaB. Trends Neurosci 34:316-325

Gutierrez H, Hale VA, Dolcet X, Davies A (2005) NF-kappaB signalling regulates the growth of neural processes in the developing PNS and CNS. Development 132:1713-1726.

Gutierrez H, O'Keeffe GW, Gavaldà N, Gallagher D, Davies AM (2008) Nuclear factor kappa B signaling either stimulates or inhibits neurite growth depending on the phosphorylation status of p65/RelA. J Neurosci 28:8246-8256.

Habecker BA, Sachs HH, Rohrer H, Zigmond RE (2009) The dependence on gp130 cytokines of axotomy induced neuropeptide expression in adult sympathetic neurons. Dev Neurobiol 69:392-400.

Haddock RE, Hill CE (2011) Sympathetic overdrive in obesity involves purinergic hyperactivity in the resistance vasculature. J Physiol 589:3289-3307.

Hasan W, Jama A, Donohue T, Wernli G, Onyszchuk G, Al-Hafez B, Bilgen M, Smith PG (2006) Sympathetic hyperinnervation and inflammatory cell NGF synthesis following myocardial infarction in rats. Brain Res 1124:142-154.

Hasking GJ, Esler MD, Jennings GL, Burton D, Johns JA, Korner PI (1986) Norepinephrine spillover to plasma in patients with congestive heart failure: evidence of increased overall and cardiorenal sympathetic nervous activity. Circulation 73:615-621.

Himura Y, Felten SY, Kashiki M, Lewandowski TJ, Delehanty JM, Liang CS (1993) Cardiac noradrenergic nerve terminal abnormalities in dogs with experimental congestive heart failure. Circulation 88:1299-1309.

Hyatt Sachs H, Rohrer H, Zigmond RE (2010) The conditioning lesion effect on sympathetic neurite outgrowth is dependent on gp130 cytokines. Exp Neurol 223:516-522.

Hymowitz SG, Filvaroff EH, Yin JP, Lee J, Cai L, Risser P, Maruoka M, Mao W, Foster J, Kelley RF, Pan G, Gurney AL, de Vos AM, Starovasnik MA (2001) IL-17s adopt a cystine knot fold: structure and activity of a novel cytokine, IL-17F, and implications for receptor binding. EMBO J 20:5332-5341.

Ibarretxe G, Perrais D, Jaskolski F, Vimeney A, Mulle C (2007) Fast regulation of axonal growth cone motility by electrical activity. J Neurosci 27:7684-7695.

Kannan Y, Bienenstock J, Ohta M, Stanisz AM, Stead RH (1996) Nerve growth factor and cytokines mediate lymphoid tissue-induced neurite outgrowth from mouse superior cervical ganglia in vitro. J Immunol 157:313-320.

Kao CY, Huang F, Chen Y, Thai P, Wachi S, Kim C, Tam L, Wu R (2005) Up-regulation of CC chemokine ligand 20 expression in human airway epithelium by IL-17 through a JAK-independent but MEK/NF-kappaBdependent signaling pathway. J Immunol 175:6676-6685.

Kim BJ, Jones HP (2010) Epinephrine-primed murine bone marrowderived dendritic cells facilitate production of IL-17A and IL-4 but not IFN-gamma by CD4+ T cells. Brain Behav Immun 24:1126-1136.

Korn T, Oukka M, Kuchroo V, Bettelli E (2007) Th17 cells: effector T cells with inflammatory properties. Semin Immunol 19:362-371.

Langrish CL, Chen Y, Blumenschein WM, Mattson J, Basham B, Sedgwick JD, McClanahan T, Kastelein RA, Cua DJ (2005) IL-23 drives a pathogenic $\mathrm{T}$ cell population that induces autoimmune inflammation. J Exp Med 201:233-240.

Leiss D, Hinz U, Gasch A, Mertz R, Renkawitz-Pohl R (1988) Beta 3 tubulin expression characterizes the differentiating mesodermal germ layer during Drosophila embryogenesis. Development 104:525-531.

Li Z, Burns AR, Han L, Rumbaut RE, Smith CW (2011) IL-17 and VEGF are necessary for efficient corneal nerve regeneration. Am J Pathol 178:1106-1116.
Littman DR, Rudensky AY (2010) Th17 and regulatory T cells in mediating and restraining inflammation. Cell 140:845-858.

Liu Y, Wu Y, Lee JC, Xue H, Pevny LH, Kaprielian Z, Rao MS (2002) Oligodendrocyte and astrocyte development in rodents: an in situ and immunohistological analysis during embryonic development. Glia 40:25-43.

Lorton D, Lubahn C, Sweeney S, Major A, Lindquist CA, Schaller J, Washington C, Bellinger DL (2009) Differences in the injury/sprouting response of splenic noradrenergic nerves in Lewis rats with adjuvant-induced arthritis compared with rats treated with 6-hydroxydopamine. Brain Behav Immun 23:276-285.

Lourenssen S, Wells RW, Blennerhassett MG (2005) Differential responses of intrinsic and extrinsic innervation of smooth muscle cells in rat colitis. Exp Neurol 195:497-507.

Manni M, Granstein RD, Maestroni G (2011) beta2-Adrenergic agonists bias TLR-2 and NOD2 activated dendritic cells towards inducing an IL-17 immune response. Cytokine 55:380-386.

McQuarrie IG, Grafstein B (1973) Axon outgrowth enhanced by a previous nerve injury. Arch Neurol 29:53-55.

McQuarrie IG, Grafstein B, Dreyfus CF, Gershon MD (1978) Regeneration of adrenergic axons in rat sciatic nerve: effect of a conditioning lesion. Brain Res 141:21-34.

Motagally MA, Lukewich MK, Chisholm SP, Neshat S, Lomax AE (2009a) Tumour necrosis factor alpha activates nuclear factor kappaB signalling to reduce $\mathrm{N}$-type voltage-gated $\mathrm{Ca} 2+$ current in postganglionic sympathetic neurons. J Physiol 587:2623-2634.

Motagally MA, Neshat S, Lomax AE (2009b) Inhibition of sympathetic $\mathrm{N}$-type voltage-gated $\mathrm{Ca} 2+$ current underlies the reduction in norepinephrine release during colitis. Am J Physiol Gastrointest Liver Physiol 296:G1077-G1084.

Murphy CA, Langrish CL, Chen Y, Blumenschein W, McClanahan T, Kastelein RA, Sedgwick JD, Cua DJ (2003) Divergent pro- and anti-inflammatory roles for IL-23 and IL-12 in joint autoimmune inflammation. J Exp Med 198:1951-1957.

Nakae S, Nambu A, Sudo K, Iwakura Y (2003) Suppression of immune induction of collagen-induced arthritis in IL-17-deficient mice. J Immunol 171:6173-6177.

Neet KE, Campenot RB (2001) Receptor binding, internalization, and retrograde transport of neurotrophic factors. Cell Mol Life Sci 58:1021-1035.

Oboki K, Ohno T, Saito H, Nakae S (2008) Th17 and allergy. Allergol Int 57:121-134

O'Keeffe GW, Gutierrez H, Pandolfi PP, Riccardi C, Davies AM (2008) NGF-promoted axon growth and target innervation requires GITRLGITR signaling. Nat Neurosci 11:135-142.

Palacios R (1982) Concanavalin A triggers T lymphocytes by directly interacting with their receptors for activation. J Immunol 128:337-342.

Park H, Li Z, Yang XO, Chang SH, Nurieva R, Wang YH, Wang Y, Hood L, Zhu Z, Tian Q, Dong C (2005) A distinct lineage of CD4 T cells regulates tissue inflammation by producing interleukin 17. Nat Immunol 6:1133-1141.

Peeker R, Aldenborg F, Dahlström A, Johansson SL, Li JY, Fall M (2000) Increased tyrosine hydroxylase immunoreactivity in bladder tissue from patients with classic and nonulcer interstitial cystitis. J Urol 163:1112-1115.

Rajan P, Stewart CL, Fink JS (1995) LIF-mediated activation of STAT proteins after neuronal injury in vivo. Neuroreport 6:2240-2244.

Rapalino O, Lazarov-Spiegler O, Agranov E, Velan GJ, Yoles E, Fraidakis M, Solomon A, Gepstein R, Katz A, Belkin M, Hadani M, Schwartz M (1998) Implantation of stimulated homologous macrophages results in partial recovery of paraplegic rats. Nat Med 4:814-821.

Roark CL, French JD, Taylor MA, Bendele AM, Born WK, O’Brien RL (2007) Exacerbation of collagen-induced arthritis by oligoclonal, IL-17-producing gamma delta T cells. J Immunol 179:5576-5583.

Rosas-Ballina M, Ochani M, Parrish WR, Ochani K, Harris YT, Huston JM, Chavan S, Tracey KJ (2008) Splenic nerve is required for cholinergic antiinflammatory pathway control of TNF in endotoxemia. Proc Natl Acad Sci U S A 105:11008-11013.

Rosas-Ballina M, Olofsson PS, Ochani M, Valdés-Ferrer SI, Levine YA, Reardon C, Tusche MW, Pavlov VA, Andersson U, Chavan S, Mak TW, Tracey KJ (2011) Acetylcholine-synthesizing T cells relay neural signals in a vagus nerve circuit. Science 334:98-101. 
Ryan SK, Shotts LR, Hong SK, Nehra D, Groat CR, Armstrong JR, McClellan AD (2007) Glutamate regulates neurite outgrowth of cultured descending brain neurons from larval lamprey. Dev Neurobiol 67:173-188.

Sann SB, Xu L, Nishimune H, Sanes JR, Spitzer NC (2008) Neurite outgrowth and in vivo sensory innervation mediated by a $\mathrm{Ca}(\mathrm{V}) 2.2$-laminin beta 2 stop signal. J Neurosci 28:2366-2374.

Schulz SM, Köhler G, Holscher C, Iwakura Y, Alber G (2008) IL-17A is produced by Th17, gammadelta $\mathrm{T}$ cells and other CD4- lymphocytes during infection with Salmonella enterica serovar enteritidis and has a mild effect in bacterial clearance. Int Immunol 20:1129-1138.

Sharon N, Lis H (1989) Lectins as cell recognition molecules. Science 246:227-234

Shen F, Gaffen SL (2008) Structure-function relationships in the IL-17 receptor: implications for signal transduction and therapy. Cytokine 41:92-104.

Siffrin V, Radbruch H, Glumm R, Niesner R, Paterka M, Herz J, Leuenberger T, Lehmann SM, Luenstedt S, Rinnenthal JL, Laube G, Luche H, Lehnardt S, Fehling HJ, Griesbeck O, Zipp F (2010) In vivo imaging of partially reversible th17 cell-induced neuronal dysfunction in the course of encephalomyelitis. Immunity 33:424-436.

Soliven B, Albert J (1992) Tumor necrosis factor modulates Ca2+ currents in cultured sympathetic neurons. J Neurosci 12:2665-2671.

Spitzer NC (2006) Electrical activity in early neuronal development. Nature 444:707-712.

Straub RH, Lowin T, Klatt S, Wolff C, Rauch L (2011) Increased density of sympathetic nerve fibers in metabolically activated fat tissue surrounding human synovium and mouse lymph nodes in arthritis. Arthritis Rheum 63:3234-3242.

The FO, Boeckxstaens GE, Snoek SA, Cash JL, Bennink R, Larosa GJ, van den Wijngaard RM, Greaves DR, de Jonge WJ (2007) Activation of the cho- linergic anti-inflammatory pathway ameliorates postoperative ileus in mice. Gastroenterology 133:1219-1228.

Vida G, Peña G, Kanashiro A, Del Rocio Thompson-Bonilla M, Palange D, Deitch EA, Ulloa L (2011) beta2-Adrenoreceptors of regulatory lymphocytes are essential for vagal neuromodulation of the innate immune system. FASEB J 25:4476-4485.

Wernli G, Hasan W, Bhattacherjee A, van Rooijen N, Smith PG (2009) Macrophage depletion suppresses sympathetic hyperinnervation following myocardial infarction. Basic Res Cardiol 104:681-693.

Wong CH, Jenne CN, Lee WY, Léger C, Kubes P (2011) Functional innervation of hepatic iNKT cells is immunosuppressive following stroke. Science 334:101-105.

Xia CM, Colomb DG Jr, Akbarali HI, Qiao LY (2011) Prolonged sympathetic innervation of sensory neurons in rat thoracolumbar dorsal root ganglia during chronic colitis. Neurogastroenterol Motil 23:801-e339.

Xie WR, Deng H, Li H, Bowen TL, Strong JA, Zhang JM (2006) Robust increase of cutaneous sensitivity, cytokine production and sympathetic sprouting in rats with localized inflammatory irritation of the spinal ganglia. Neuroscience 142:809-822.

Yao Z, Fanslow WC, Seldin MF, Rousseau AM, Painter SL, Comeau MR, Cohen JI, Spriggs MK (1995a) Herpesvirus saimiri encodes a new cytokine, IL-17, which binds to a novel cytokine receptor. Immunity 3:811-821.

Yao Z, Painter SL, Fanslow WC, Ulrich D, Macduff BM, Spriggs MK, Armitage RJ (1995b) Human IL-17: a novel cytokine derived from T cells. J Immunol 155:5483-5486.

Yen D, Cheung J, Scheerens H, Poulet F, McClanahan T, McKenzie B, Kleinschek MA, Owyang A, Mattson J, Blumenschein W, Murphy E, Sathe M, Cua DJ, Kastelein RA, Rennick D (2006) IL-23 is essential for T cellmediated colitis and promotes inflammation via IL-17 and IL-6. J Clin Invest 116:1310-1316. 